\title{
Exhaust Acoustic Optimization for Improved Fuel Efficiency using GT-Power Integrated with modeFRONTIER
}

\author{
Mylaudy Dr. S. Rajadurai ${ }^{1}$, K.J.Rajakumar ${ }^{2}$ \\ ${ }^{1}$ Head $R \& D,{ }^{2}$ Assistant Manager, \\ Sharda Motor Industries Ltd. - R\&D Center, Mahindra World City, New Chennai, Tamil Nadu - 603 002, India
}

\begin{abstract}
Automotive system assemblies are mandated to have increased safety, reliability, emission/noise performance, comfort and value. Carbon dioxide regulations in CAFÉ norms from $130 \mathrm{~g} / \mathrm{km}$ in 2017 to $113 \mathrm{~g} / \mathrm{km}$ in 2022 change in base reference is very huge in terms of fuel efficiency improvement from $15 \%$ to $30 \%$ in 2022 . Acoustic optimization in exhaust system with reduced back pressure needs a systematic development process. This paper establishes a systematic and sequential optimization process to improve engine performance with high fuel efficiency by tracing out the sensitive parameters in muffler that cause severity in achieving non-complimentary and imperative acoustic targets. 1D simulation tool GT-Power integrated with modeFRONTIER is used to execute several DOE (Design of Experiment) to optimize the muffler internals. 1.2L, 3 cylinder gasoline engine performances were analyzed and plotted in different pictorial analysis charts. As the result of statistic and optimized analysis $4 \mathrm{~dB}(\mathrm{~A})$ noise reduction at $1500 \mathrm{rpm}$ in 3rd order noise level with $14 \%$ reduced back pressure was achieved. Adopting the optimization technology reduces development stage by minimizing the number of iterations and it reduces the development cost.
\end{abstract}

Keywords — Exhaust Noise Level; Fuel Efficiency; Carbon dioxide; Backpressure;, Muffler; Design of Experiment; Optimization; Order Noises; Scatter Matrix; Bubble Chart

\section{Introduction}

The value of the automobile is measured in terms of better fuel efficiency and the emission / noise performance. Mufflers are designed not only to reduce exhaust noise levels but also to improve engine fuel efficiency with reduced backpressure. In general exhaust backpressure of the engines has exponential and direct impact on fuel efficiency $(\%)$ as shown in Fig.1 and Carbon dioxide $\left(\mathrm{CO}_{2}\right)$ levels [4].

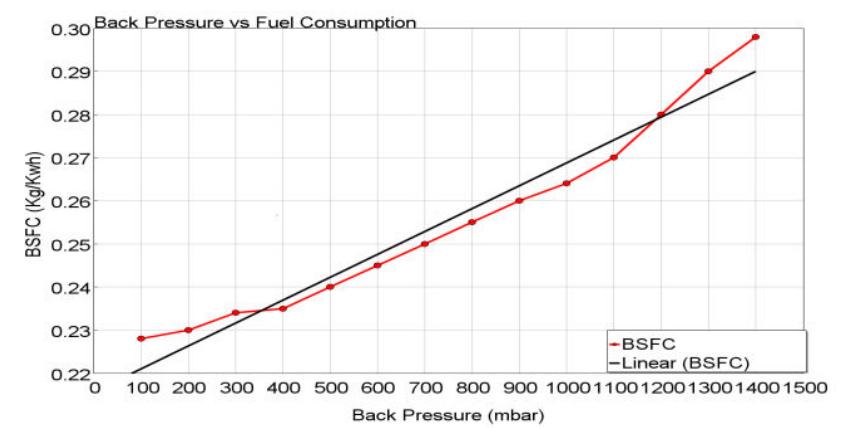

Fig. 1: Exhaust backpressure vs. Fuel consumption

A good muffler must possess low noise levels and low back pressure level. Traditional muffler development includes development of base designs in 1D simulation tool followed by proto preparation and validation of those base designs. Here challenges faced by acoustic designers are the critical or abnormal sound signatures observed in real testing, were it cannot be able to predict in 1D simulation. In current years, required sound signatures can be achieved by various design optimization tool that also leads to performance improvement, weight reduction, quick problem solving solution and cost reduction. Acoustic optimization is a method of producing several DOE's from single base design. Optimization tools apply the probability and orthogonal array theory on input parameters for the user defined constraints and objectives.

\subsection{Forecast Fuel Efficiency Improvement 2022}

Corporate Average Fuel Efficiency/Economy (CAFÉ) norms have been revised in developing nations for the improvement of fuel efficiency. The goal is to lower the fuel consumptions of vehicles by lowering the carbon dioxide $\left(\mathrm{CO}_{2}\right)$. BS VI focuses on other harmful exhaust from vehicles while CAFÉ regulations pursuit to reduce the $\mathrm{CO}_{2}$ levels.

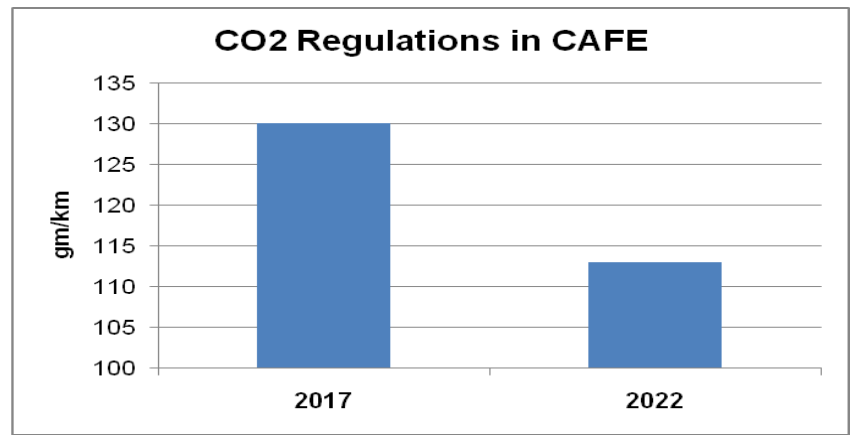

Fig. 2: Changes on $\mathrm{CO} 2$ regulations in CAFÉ norms

From above figure the changes in $\mathrm{CO} 2$ regulations has the huge difference in fuel efficiency (\%) for upcoming 
years. As per norms, fuel efficiency need to improve for $15 \%$ to $30 \%$ in 2022 to meet the $\mathrm{CO} 2$ levels. Hence exhaust backpressure has to be reduced to meet the fuel efficiency.

In this paper, a systematic optimization of exhaust muffler for improved fuel efficiency in $1.2 \mathrm{~L}$ naturally aspirated gasoline engine muffler were done to resolve the noise issue in the lower RPM with reduced backpressure. The content of this paper at first to address the problem description observed at lower RPM in engine harmonic order noise level, followed by work steps and flow chart for optimization in modeFRONTIER, followed by post processing analysis on performance of several DOE's. This optimization includes pre-processing in modeFRONTIER, processing in GT-Power, and post-processing in modeFRONTIER. The acoustic optimization in modeFRONTIER helps out to find the occurrence of severity parameters in muffler designs that affect performance of noise and fuel efficiency (backpressure).

\section{Problem Description}

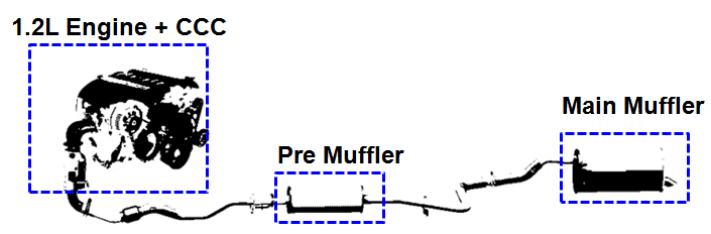

Fig. 3: Exhaust line with pre muffler \& main muffler

Fig.3 Illustrate the exhaust layout for 1.2L, 3 cylinder gasoline engine exhaust system design. As per ISO 5130 standards, exhaust tail pipe noise was measured in 3rd gear WOT (Wide Open Throttle) condition. During development every conceptual design of muffler internals observed abnormal noise at low frequency in 3rd order noise level. This C3 noise level doesn't meet the noise target and audible to in-cabin passenger ear level. Confirmation on this abnormal occurrence in the exhaust system was done by exhaust noise isolation test. There was some readily available solution, increase backpressure to avoid this abnormal noise. Backpressure and noise are two non-complimentary parameters in the exhaust development. Stage wise development of pre mufflers and main mufflers internals are shown in Fig. 4.

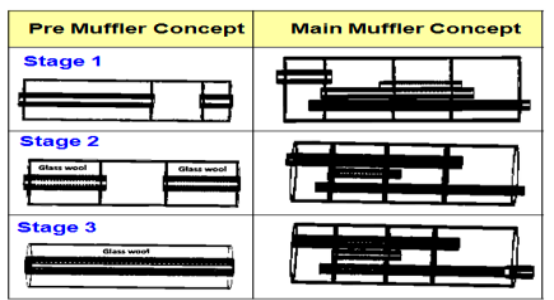

Fig. 4: Conceptual design of pre and main mufflers at different stage

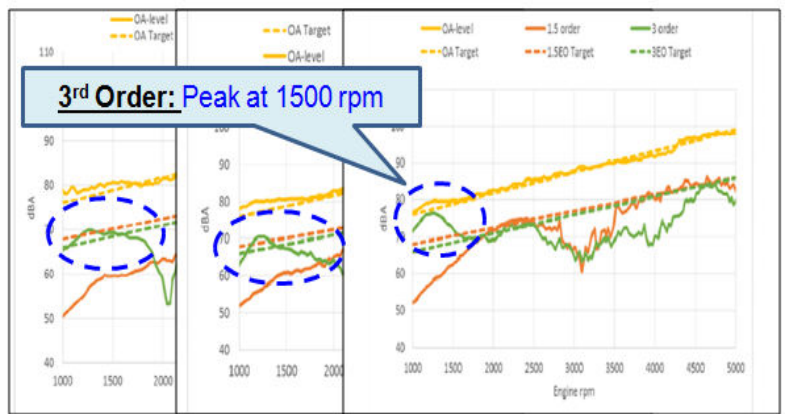

Fig. 5: Exhaust tail pipe noise test results

As shown in Figure 5. There was a peak observed at $1500 \mathrm{rpm}$ in $3 \mathrm{rd}$ order noise level in every development stage (Green curve in graph) and it doesn't meet the target line in the $1500 \mathrm{rpm}$ range. Hence our goal is to trace out the parameter that causing this severity in occurrence of noise level with reduced backpressure.

\section{Base Design Development}

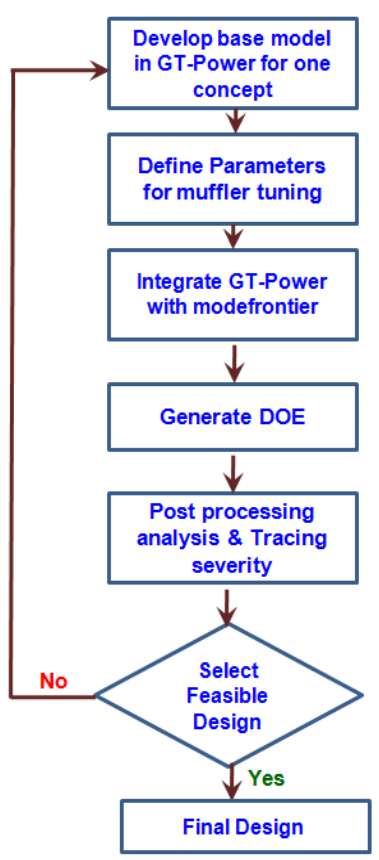

Fig. 6: General work flow for optimization

Figure 6 illustrates the step by step process for base muffler optimization in GT-Power integrated with modeFRONTIER. Initially base model that required for optimization was developed in GT-Power and muffler tuning parameters are defined in modeFRONTIER with range limits form minimum to maximum for every design parameters. In this study stage 3 pre muffler and main mufflers designs are selected as a base model for acoustic optimization (refer Fig.4). 


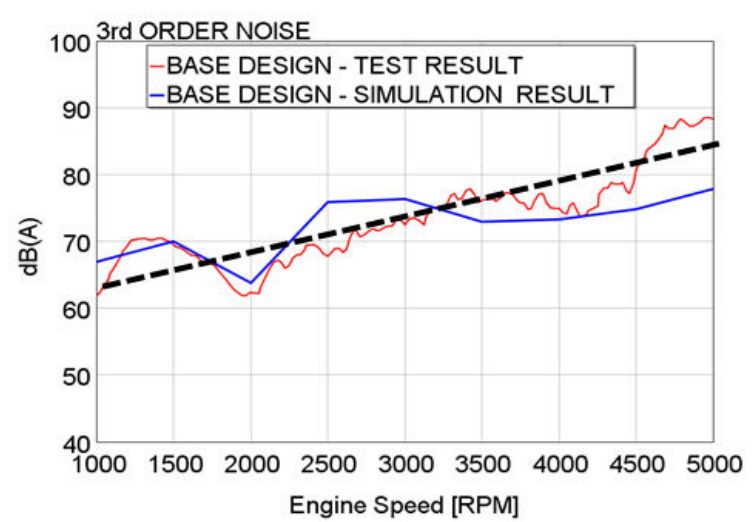

Fig. 7: Engine speed vs. Sound pressure level (Base design).

Figure 7 shows the correlation of simulation and test result for third order noise level in GT- Power. From the above results, stage 3 muffler design doesn't meet noise target from 1000 to $1500 \mathrm{rpm}$ in both simulation and test results. The main objective of this optimization is to reduce the peak at $1500 \mathrm{rpm}$ and to meet the noise target.

\section{Optimization Work Flow}

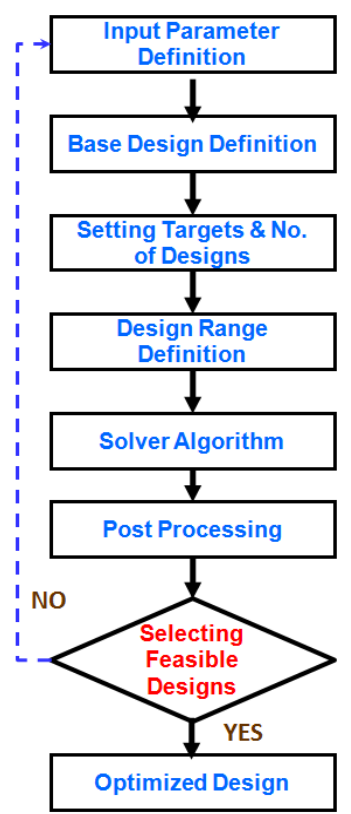

Fig. 8: Work flow in modeFRONTIER.

As per figure 8, work flow in modeFRONTIER, input parameters for tuning the base mufflers has been defined along with the design range limits. Then number of designs (DOE) has been set along with solver algorithm. For our application ULH (Uniform Latin Hypercube) algorithm is used for optimizing the base designs. Targets for all output parameters like overall noise levels, engine order noises and back pressure has been defined with respective objectives and constrains.

\section{Acoustic Tuning Parameters}

\subsection{Input Parameters}

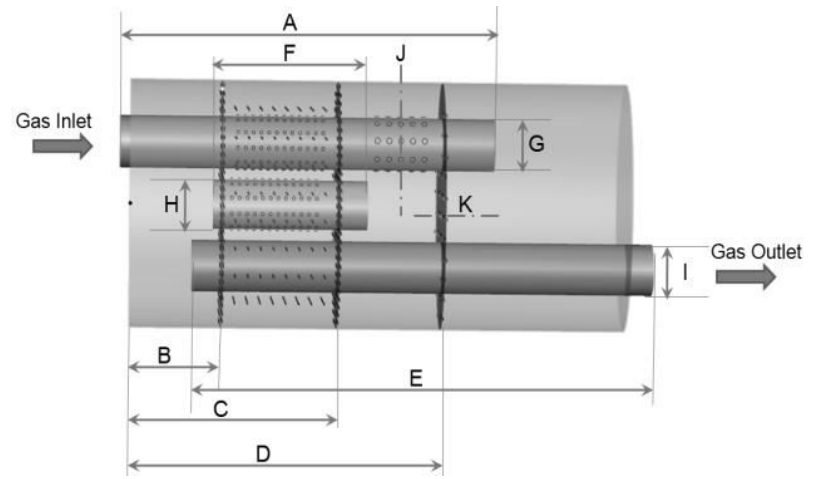

Fig. 9: Main muffler base design tuning parameters

Figure 9 shows the acoustic design optimization parameters of main muffler. In order to predict the effect of main muffler, the optimization work is carried out only for main muffler with same pre muffler design.

\begin{tabular}{|l|l|l|}
\hline Parameter & Description & Range (mm) \\
\hline A & Inlet tube length & 300 to 430 \\
\hline B & Baffle A Location & 45 to 110 \\
\hline C & Baffle B Location & 160 to 250 \\
\hline D & Baffle C Location & 260 to 320 \\
\hline E & Outlet tube length & Fixed \\
\hline F & Intermediate tube length & 140 to 250 \\
\hline G & Inlet tube diameter & 35 to 45 \\
\hline H & Intermediate tube diameter & 35 to 40 \\
\hline I & Outlet tube diameter & 35 to 40 \\
\hline J & Inlet tube perforation numbers & 40 to 80 EA \\
\hline K & Baffle C perforation numbers & 50 to 150 EA \\
\hline
\end{tabular}

Table 1. Parameter range definition

Table 1 shows the list of main muffler tuning parameter and its design range in upper and lower limits. All dimensions of internal components are in $\mathrm{mm}$, while perforation parameters are in numbers (EA). Since the length of muffler is constant so outlet tube length is same for all DOE throughout the optimization.

\subsection{Output Parameters}

For the 3 cylinder engine corresponding dominant engine harmonic orders are 1.5th and 3rd orders, etc..,. Performance of the muffler can be evaluated through the

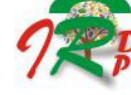


parameters like overall noise level, order noise levels and exhaust back pressure.

\subsection{ModeFRONTIER Workflow}

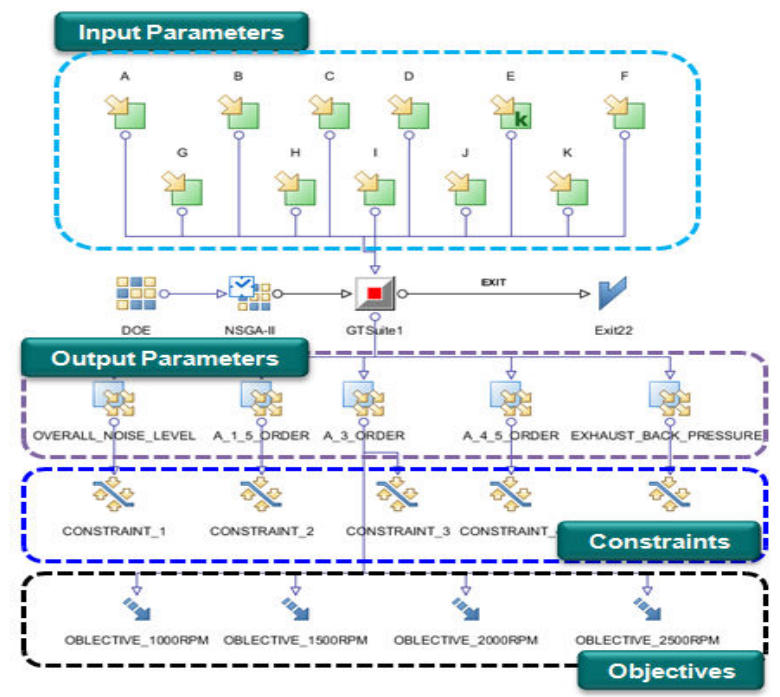

Fig. 10: ModeFRONTIER work flow window

Figure 10 shows the modeFRONTIER workflow containing all input and output parameters along with constraints and objectives. Constraints are set for each output parameters. Each constraint has the target value for every output parameters from 1000 to $5000 \mathrm{rpm}$ range. All design constraints are directed to meet performance below target line as shown in Fig 11.

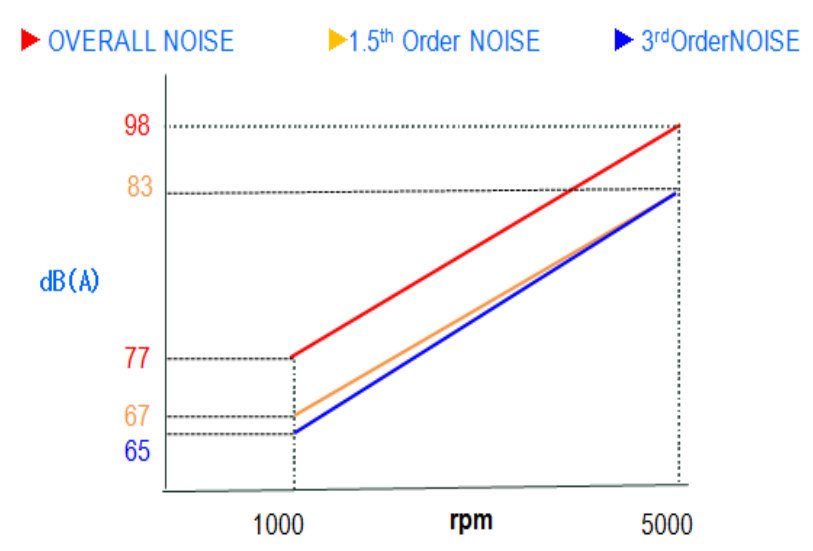

Fig. 11: Acoustic targets for exhaust system

Special objectives are defined to reduce noise level in 3rd order noise level from 1000 to $2500 \mathrm{rpm}$ range. Then the solver is commanded to generate 100 optimized designs to meet the defined constraints and objectives.

\section{Post Processing Analysis}

\subsection{Design Filters}

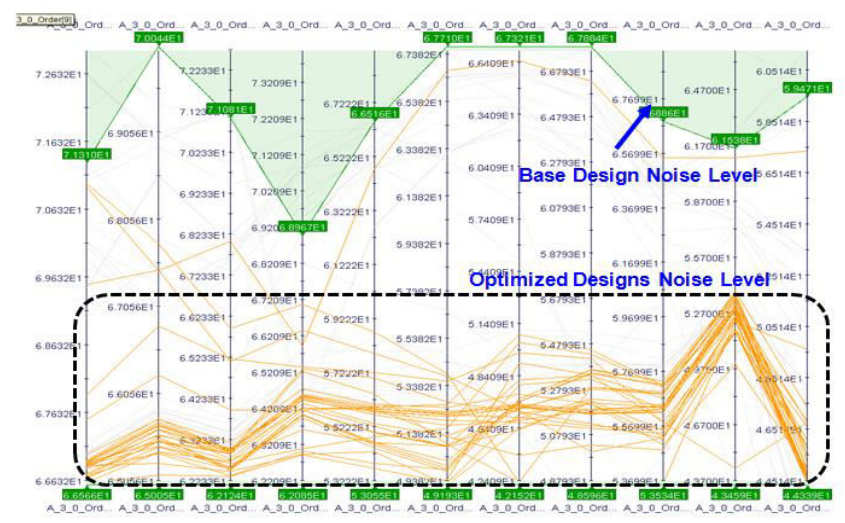

Fig. 12: Design filter chart for 3rd order noise level

Figure. 12 Illustartes the design filter chart plotted interms of RPM versus 3rd order noise level in $\mathrm{dB}(\mathrm{A})$. Outof 100 optimized designs, designs below the base system noise levels are highlighted and remaining designs are filtered out. Any of the optimized design can be selected according to the manufacturing feasibility. In modeFRONTIER, performance for each DOE's can be compared in post processing analysis with pictorial charts like parallel coordinate charts, bubble charts, scatter matrix.

\subsection{Bubble Chart}

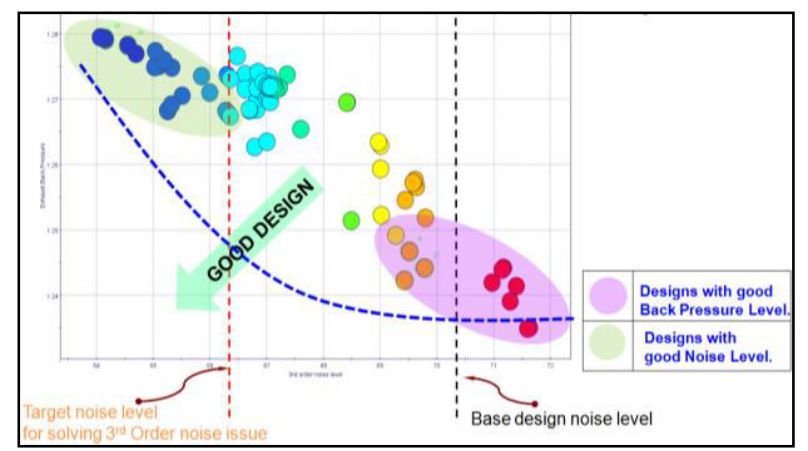

Fig. 13 Bubble chart

(3rd Order noise level vs. Exhaust back pressure)

Each and every bubble shown in figure 13 represents one optimized design, plotted in terms of 3rd order noise level at $1500 \mathrm{rpm}$ versus exhaust back pressure level at maximum rpm. The designs with good back pressure level are highlighted in pink color region and designs with low noise levels are highlighted in green color. For clearing peak at lower rpm noise level and to meet performance target, the optimized design must be somewhere in highlighted green region. 


\subsection{Sensitivity Chart}

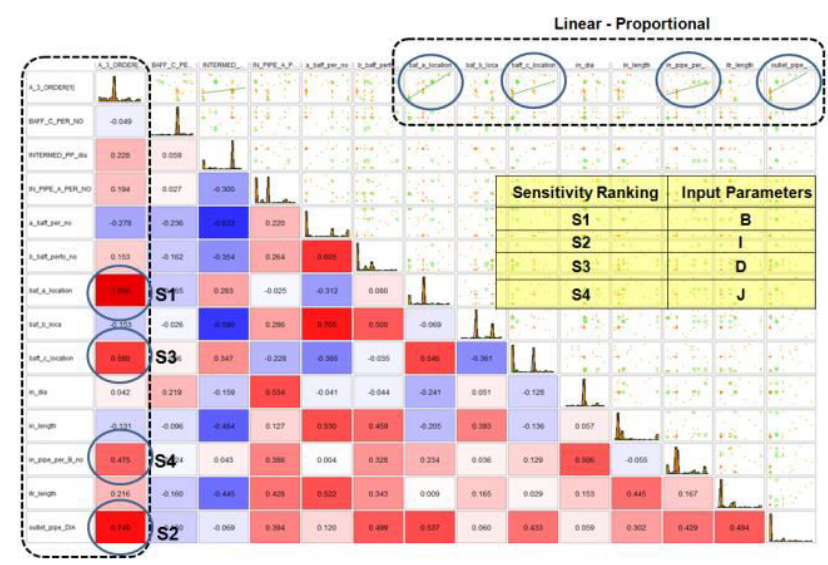

Fig. 14: Sensitivity chart for 3rd order noise level at $1500 \mathrm{rpm}$

Figure 14 illustrates the sensitivity matrix of every input parameter that has direct effect on increasing the 3rd order noise level at $1500 \mathrm{rpm}$. From above chart four parameters are suspected which are linearly proportional to the increasing noise level at $1500 \mathrm{rpm}$. First dominant parameter is B (Baffle A Location). If the location of baffle $A$ is increased then 3 rd order noise level at $1500 \mathrm{rpm}$ is also increased. Similarly other parameters I (Outlet tube diameter), D (Baffle C Location), J (Inlet tube perforation numbers) are also linearly proportional to the increase of noise level at $1500 \mathrm{rpm}$.

\section{Optimized Design}

From the above post processing analysis the best optimized design can be selected. According to the manufacturing feasibility the optimized design parameters are listed below. Table 2 illustrates the parameters and their ranges of base design and optimized design in main muffler.

Table 2: Sensitive parameters value for base and optimized design

\begin{tabular}{|l|l|l|l|}
\hline Parameter & Description & Base Design & $\begin{array}{l}\text { Optimized } \\
\text { Design }\end{array}$ \\
\hline B & Baffle A Location & $110 \mathrm{~mm}$ & $53 \mathrm{~mm}$ \\
\hline I & $\begin{array}{l}\text { Outlet tube } \\
\text { diameter }\end{array}$ & $40 \mathrm{~mm}$ & $35 \mathrm{~mm}$ \\
\hline D & Baffle C Location & $320 \mathrm{~mm}$ & $290 \mathrm{~mm}$ \\
\hline J & $\begin{array}{l}\text { Inlet tube } \\
\text { perforation numbers }\end{array}$ & $41 \mathrm{EA}$ & $80 \mathrm{EA}$ \\
\hline
\end{tabular}

\section{Results and Conclusion}

After refining the values of input parameters based on manufacturing feasibility in modeFRONTIER same has been applied in GT-Power main muffler design for reconfirmation. For the optimized design at $1500 \mathrm{rpm}$, 3rd order was well reduced and meets the noise targets as shown in below figure 15 .

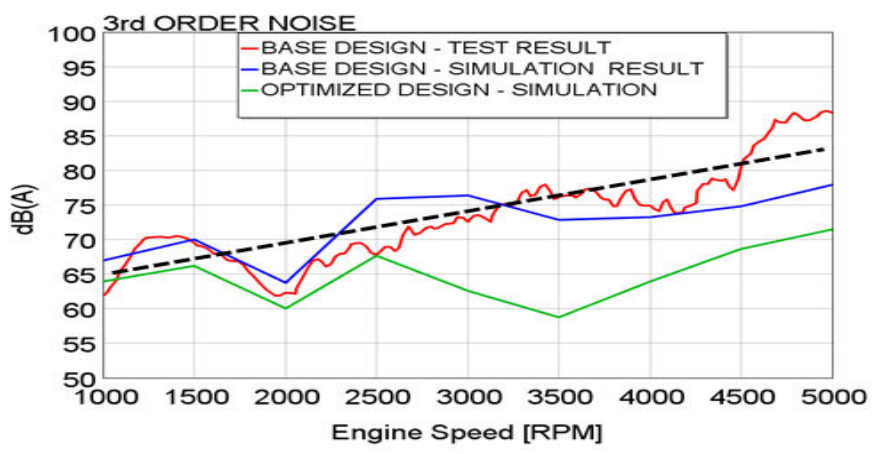

Fig. 15: 3rd order noise level for base $\&$ optimized design

From the above graph the noise level for the base design at $1500 \mathrm{rpm}$ is $70 \mathrm{~dB}$ (A) and the levels for optimized design at same rpm is $66 \mathrm{~dB}(\mathrm{~A}) .4 \mathrm{~dB}(\mathrm{~A})$ reduction improvement was observed in lower rpm from the optimized design, with reduced backpressure performance as shown in Figure 16. The predicted back pressure for the cold end system base design is $39 \mathrm{kPa}$ and for the optimized design the predicted backpressure is 33.5 $\mathrm{kPa}$, where target backpressure is $38 \mathrm{kPa}$. $14 \%$ backpressure improvement was achieved by this systematic optimization approach.

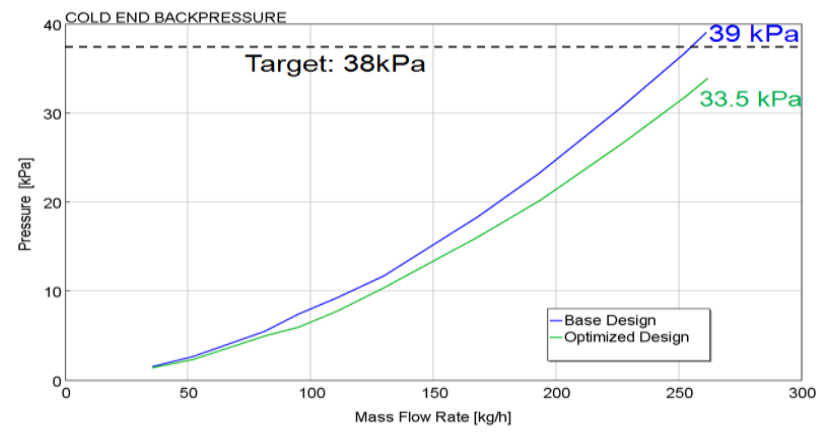

Fig. 16: Backpressure performance for base and optimized design

\section{References}

[1] MurariMohon Roy, Mohammad UzzalHossainJoardder and Md. ShazibUddin, (2010), "Effect of Engine Backpressure on the Performance and Emissions of a CI Engine" The 7th Jordanian International Mechanical Engineering Conference (JIMEC'7) 27 29 September 2010, Amman - Jordan.

[2] HONG Han-chi, HUANG Hong-wu, BAI Yi-jie, (2012) "Optimization of Intake and Exhaust System for FSAE Car Based on Orthogonal Array Testing", International Journal of Engineering and Technology Volume 2 No. 3, March, 2012.

[3] Hanjun Dai, Elias B. Khalil, Yuyu Zhang, Bistra Dilkina†, Le Song "Learning Combinatorial Optimization Algorithms over Graphs".

[4] Rajadurai.S, Naveen.S (2015) " Muffler Optimization for Increased Fuel Efficiency Iterations Using Taguchi Orthogonal Array for Controlling CO2", IJISET - International Journal of Innovative Science, Engineering \& Technology, Vol. 2 Issue 3. 